\title{
PLASMA LH OF THE PREPUBERTAL LAMB: A POSSIBLE EARLY INDICATOR OF FECUNDITY
}

\author{
B. M. BINDON AND HELEN N. TURNER \\ CSIRO Division of Animal Genetics, P.O. Box 90, \\ Epping, N.S.W. 2121, Australia
}

(Received 19th October 1973)

Genetic differences in fecundity have arisen as a result of selection for litter size in Merino sheep since 1954. The selection experiment involves three flocks designated ' $\mathrm{O}$ ', ' $\mathrm{T}$ ' and ' $\mathrm{B}$ ' and their genetic history has been described by Turner (1969). In the ' $O$ ' flock, in which selection has been against multiple births, the ewes regularly have a low $(0$ to $10 \%)$ incidence of twin births. The ' $\mathrm{T}$ ' and ' $\mathrm{B}$ ' flocks have a medium (50 to $60 \%$ ) and high (70 to $80 \%$ ) incidence of multiple births. In the 'B' flock, about $30 \%$ of ewes have triplets and $10 \%$ have quadruplets or quintuplets each year.

Gurrent research on these groups is designed to examine the endocrine changes that have accompanied the genetic divergence in fecundity. It is known that ewes from the flocks of high fecundity have a higher ovulation rate and shed more eggs in response to exogenous gonadotrophin (Bindon, Ch'ang \& Turner, 1971). The present report deals with the plasma LH levels of young lambs from the three groups. Peripheral plasma samples were collected between 09.00 and 10.00 hours on about the 30th day of life (range 27 to 33 days) and LH was measured by radioimmunoassay (Goding \& co-authors, 1969). The results were expressed in terms of ng NIH-LH-S16 per ml plasma. In this report, data from male and female lambs have been pooled, although there has been a slight but consistent difference in LH levels in favour of ewe lambs. In 1970, only female lambs were examined and a sample only of the three populations included. In 1971 and 1972, all lambs of both sexes were studied.

Table 1 presents the $\mathrm{LH}$ data in the form of mean values and also a frequency distribution showing the percentages of individuals exceeding 3,10 and $20 \mathrm{ng} \mathrm{LH} / \mathrm{ml}$. This illustrates the occurrence of some elevated $\mathrm{LH}$ values in the ' $T$ ' and ' $B$ ' groups. Significant non-homogeneity of variances precludes a comparison of the means. Transformation of the data did not equalize the variances. Chi-square analysis of the overall proportions of lambs with elevated LH levels $(>3 \mathrm{ng} / \mathrm{ml}$ ), however, indicates a highly significant difference between the ' $O$ ' group and the ' $T$ ' and ' $B$ ' groups (Table 1 ). There was also a significant difference between the ' $T$ ' and ' $B$ ' groups in the proportion of lambs with $\mathrm{LH}$ exceeding 10 and $20 \mathrm{ng} / \mathrm{ml}$. The highest $\mathrm{LH}$ levels were recorded in 'B' lambs.

In the 'B' group there was an interesting effect of litter size on LH levels. The pooled data for 3 years indicate that triplet and quadruplet lambs in this 
group had higher LH (>3 ng/ml) on Day 30 than singletons or twins (Table 2). Singletons were not significantly different from twins, nor triplets from quadruplets. No significant effect of litter size on $\mathrm{LH}$ values was observed in the ' $T$ ' flock.

In 1972, the short-term $\mathrm{LH}$ fluctuations in ' $\mathrm{O}$ ', ' $\mathrm{T}$ ' and ' $\mathrm{B}$ ' lambs were examined with a view to interpreting the high $\mathrm{LH}$ levels seen in some ' $\mathrm{T}$ ' and 'B' lambs sampled once only on Day 30. Plasma LH was measured at 09.00, $12.00,15.00$ and 18.00 hours for each lamb. There were approximately equal numbers of male and female lambs, aged exactly 30 days, and all were studied on the one day. The results in Table 3 show that, in lambs from the ' $O$ ' group,

Table 1. Plasma $\mathrm{LH}$ levels and frequency distribution of $\mathrm{LH}$ values for lambs from flocks with a low $(\mathrm{O})$, medium $(\mathrm{T})$ and high $(\mathrm{B})$ incidence of multiple births

\begin{tabular}{|c|c|c|c|c|c|}
\hline \multirow{2}{*}{ Flock } & \multirow{2}{*}{$\begin{array}{l}\text { No. } \\
\text { of } \\
\text { lambs }\end{array}$} & \multirow{2}{*}{$\begin{array}{c}\text { Mean } \\
L H \\
(n g / m l)\end{array}$} & \multicolumn{3}{|c|}{$\%$ of lambs with $L H$ level: } \\
\hline & & & $>3 \mathrm{ng} / \mathrm{ml}$ & $>10 \mathrm{ng} / \mathrm{ml}$ & $>20 \mathrm{ng} / \mathrm{ml}$ \\
\hline $\begin{array}{l}\text { 'O' } \\
\text { 'T' } \\
\text { 'B' }\end{array}$ & $\begin{array}{l}174 \\
399 \\
487\end{array}$ & $\begin{array}{l}1 \cdot 6 \\
2 \cdot 4 \\
3 \cdot 0\end{array}$ & $\begin{array}{r}5 \cdot 2 \\
21 \cdot 3 \\
23 \cdot 8\end{array}$ & $\begin{array}{l}0 \cdot 6 \\
2 \cdot 3 \\
5 \cdot 5\end{array}$ & $\begin{array}{l}0 \\
0 \cdot 3 \\
2 \cdot 3\end{array}$ \\
\hline \multicolumn{3}{|c|}{ Between flock comparisons } & $\begin{array}{c}\chi_{(2)}^{2}=28.9 \\
P<0.001\end{array}$ & $\chi_{(1)}^{2}$ (i.e. 'T' versus 'B') $=6.1$ & $\chi_{(1)}^{2}$ (i.e. 'T' versus $^{\prime} \mathrm{B}$ ') $=6.6$ \\
\hline
\end{tabular}

The lambs were examined between 09.00 and 10.00 hours on Day 30 of life.

The results represent the pooled data for male and female lambs born in 1970, 1971, and 1972.

Table 2. Effect of litter size on the plasma LH levels on Day 30 of life of ' $T$ ' and ' $\mathrm{B}$ ' lambs born in 1970, 1971 and 1972

\begin{tabular}{|c|c|c|c|c|c|c|}
\hline \multirow{2}{*}{ Flock } & \multirow{2}{*}{ Litter size } & \multirow{2}{*}{$\begin{array}{c}\text { No. } \\
\text { of } \\
\text { lambs }\end{array}$} & \multirow{2}{*}{$\begin{array}{c}\text { Mean } \\
\text { LH } \\
(n g / m l)\end{array}$} & \multicolumn{3}{|c|}{$\%$ of lambs with $L H$ level: } \\
\hline & & & & $>3 n g / m l^{*}$ & $>10 \mathrm{ng} / \mathrm{ml}$ & $>20 \mathrm{ng} / \mathrm{ml}$ \\
\hline ' $\mathrm{T}$ ' & $\begin{array}{l}\text { Singleton } \\
\text { Twin }\end{array}$ & $\begin{array}{l}106 \\
293\end{array}$ & $\begin{array}{l}2 \cdot 7 \\
2 \cdot 3\end{array}$ & $\begin{array}{l}20 \cdot 9 \\
23 \cdot 1\end{array}$ & $\begin{array}{l}4 \cdot 1 \\
2 \cdot 8\end{array}$ & $\begin{array}{l}0 \cdot 9 \\
0\end{array}$ \\
\hline 'B' & $\begin{array}{l}\text { Singleton }(S) \\
\text { Twin }(T) \\
\text { Triplet }(T r) \\
\text { Quadruplet (Q) }\end{array}$ & $\begin{array}{r}83 \\
210 \\
143 \\
51\end{array}$ & $\begin{array}{l}2 \cdot 4 \\
2 \cdot 8 \\
4 \cdot 1 \\
3 \cdot 7\end{array}$ & $\begin{array}{l}20 \cdot 5 \\
18 \cdot 1 \\
30 \cdot 8 \\
31 \cdot 4\end{array}$ & $\begin{array}{l}2 \cdot 4 \\
3 \cdot 8 \\
8 \cdot 4 \\
7 \cdot 8\end{array}$ & $\begin{array}{l}1 \cdot 2 \\
0 \\
3 \cdot 5 \\
3 \cdot 9\end{array}$ \\
\hline
\end{tabular}

For abbreviations, see Table 1

* In 'B' flock, $\chi_{(1)}^{2}$ [i.e. $(\mathrm{S}+\mathrm{T})$ versus $\left.(\mathrm{Tr}+\mathrm{Q})\right]=12.5 ; P<0.001$.

LH levels were low and stable throughout the day, and only exceeded $3 \mathrm{ng} / \mathrm{ml}$ in one of the fifty-six samples. The mean LH levels in ' $T$ ' and ' $B$ ' lambs were higher than in the ' $\mathrm{O}$ ' group; this was due to the occurrence of significant peaks of $\mathrm{LH}$ in some ' $\mathrm{B}$ ' and ' $\mathrm{T}$ ' lambs. The number and height of $\mathrm{LH}$ peaks were substantially higher in ' $B$ ' than in ' $T$ ' lambs (see range of values in Table 3 ). Almost half the ' $B$ ' lambs had $\mathrm{LH}$ peaks exceeding $3 \mathrm{ng} / \mathrm{ml}$, and one quarter had peaks greater than $10 \mathrm{ng} / \mathrm{ml}$. Elevated $\mathrm{LH}$ values were not confined to any particular time of day. Some ' $B$ ' lambs had up to three LH peaks but all had at least one baseline value (i.e. 1 to $2 \mathrm{ng} / \mathrm{ml}$ ), indicating episodic LH release. 


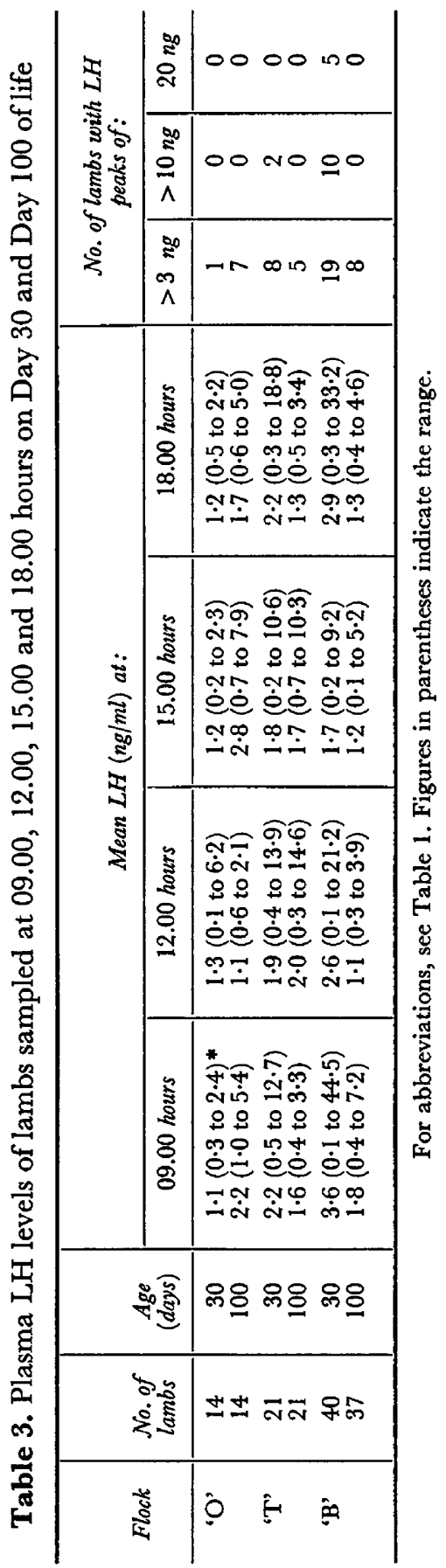


Similar LH patterns in female lambs have been reported by Foster, Lemons \& Niswender (1972).

This study was repeated on the same lambs when they were 100 days old. The results in Table 3 show that ' $B$ '-group lambs, in particular, had ceased to show the high $\mathrm{LH}$ values seen at Day 30. By contrast, the ' $\mathrm{O}$ '-group lambs had slightly higher LH levels than at Day 30, the samples from half the lambs showing modest peaks of LH. It appears that the episodic LH release pattern was only transient, but occurred earlier in life in ' $B$ ' and ' $T$ ' lambs than ' $O$ ' lambs.

These results are of interest from two points of view. Firstly, it may be possible to use LH differences early in life as an aid to selection for fecundity. Selection could be carried out directly in the male since the character is expressed in both sexes. Fluctuation of LH throughout the day does present the difficulty of knowing when to make the LH measurement. The present data suggest that it might be most useful to discriminate between those lambs experiencing $\mathrm{LH}$ fluctuation and those that are not. This should be possible by making several LH measurements at intervals which are less than the half-life (30 min) of LH. Another approach being investigated is to measure the LH release induced by synthetic gonadotrophin-releasing hormone. Secondly, it is important to understand the effects that elevated LH levels early in life may have on the gonad. Differences in the rate of testis growth appear to be one effect (Land, 1973). Lambs of high fecundity in the present selection experiment began experiencing substantial LH releases by Day 30. Exposure of the ovary to periodic LH stimulation early in life may have contributed to the differences in ovulation rate that ' $O$ ', ' $T$ ' and ' $B$ ' lambs displayed after puberty.

This work was financed by the Australian Wool Corporation and the Australian Meat Research Committee.

\section{REFERENGES}

Bindon, B. M., GH'ANG, T. S. \& TuRner, H. N. (1971) Ovarian response to gonadotrophin by Merino ewes selected for fecundity. Aust. F. agric. Res. 22, 809.

Foster, D. L., Lemons, J. A. \& Niswender, G. D. (1972) Sequential patterns of LH/FSH during sexual development of female lambs. 4th Int. Congr. Endocr., p. 101. Excerpta Medica Int. Congr. Series.

Goding, J. R., Gatt, K. J., Brown, J. M., Kaltenbach, G. C., Gumming, I. A. \& Mole, B. J. (1969) Radioimmunoassay for ovine luteinizing hormone. Secretion of luteinizing hormone during estrus and following estrogen administration in the sheep. Endocrinology, 85, 133.

LAND, R. B. (1973) The expression of female sex-limited characters in the male. Nature, Lond. 241, 208.

Turner, H. N. (1969) Effect of selection on lambing rates. In Reproduction Symposium, U.S. Sheep Development Programme, Stillwater, Oklahoma, p. 67. Ed. G. Scott. University of Colorado. 